\title{
Clinical determinants of early parasitological response after ACT treatment in patients diagnosed with uncomplicated malaria in Africa: a pooled analysis of individual patient data
}

\author{
Prabin Dahal ${ }^{1,2^{*}}$, WWARN ACT Africa Baseline Study Group ${ }^{1}$ \\ From Challanges in malaria research: Core science and innovation \\ Oxford, UK. 22-24 September 2014
}

\section{Background}

Artemisinin resistant $P$. falciparum malaria has emerged in Western Cambodia and now has been observed in Thailand, Vietnam and Myanmar and Lao. In addition, there is a recent report of a Vietnamese patient, apparently infected with P. falciparum in Angola, who was unresponsive to artemisinin treatment. This makes it even more urgent to have baseline information on early parasite response to ACTs in African patients, the first step in establishing surveillance for this important phenotype.

\section{Materials and methods}

Individual patient data from efficacy trials conducted between 1999 and 2012 were shared with the Worldwide Antimalarial Resistance Network (WWARN) and pooled analyses conducted using standardized methodology. Factors affecting early parasitological response to treatment were investigated using logistic regression with study sites fitted as a random effect.

\section{Results}

Data from 85 studies $(\mathrm{N}=29,664)$ conducted in 27 countries with Artemether-lumefantrine ( $\mathrm{AL}, \mathrm{n}=13,664)$, Artesunate-amodia-quine-fixed dose combination (ASAQ-F; $\mathrm{n}=4,097$ ), Artesunate-amodiaquine-co-blister combination (ASAQ-C; $\mathrm{n}=2,505$ ), Artesunate-amodiaquine-loose combination (ASAQ-L; $\mathrm{n}=4,096$ ), and $\mathrm{Di}$ hydro artemisinin-piperaquine (DP; $\mathrm{n}=4,492$ ) were included. With all drugs tested, high baseline parasite density and fever were both independent predictors of persistent parasitemia on days 1, 2 and 3. Adjusted for these variables, patients from 1 to 5 years and from 5 to 12 years in areas of low/moderate transmission were at a 2 -fold and 4-fold risk of persistent parasitemia on day 3 compared to patients of the same age-group in high transmission settings. Treatment with AL was associated with a higher risk of persistent parasitemia on day 1 $(\mathrm{AOR}=1.57$ [95\% CI: 1.38-1.78], $P<0.001)$ and day 2 $(\mathrm{AOR}=1.21$ [95\% CI: 1.01-1.45], $P=0.043)$ compared to treatment with DP. Treatment with ASAQ-L was also associated with a higher risk of persistent parasitemia on day $2(\mathrm{AOR}=1.59$ [95\% CI: $1.16-2.18], P=0.004)$ and day $3(\mathrm{AOR}=2.62$ [95\% CI: $1.24-5.53$ ], $P=0.012) \mathrm{com}-$ pared to treatment with DP.

\section{Conclusions}

These results show no evidence of slow parasite clearance in these African studies. The greatest risk of slow clearance was observed in patients from areas of low/ moderate transmission. The threshold for suspected diminished parasite susceptibility to artemisinins on day 3 was estimated to be $5 \%$, much lower than the currently used World Health Organisation threshold of $10 \%$. However, there are clear gaps in surveillance and any sites exceeding the day 3 parasite positivity rate of $5 \%$ should be further investigated.

\section{Acknowledgements}

A full list of the Worldwide Antimalarial Resistance Network ACT Africa baseline study group members can be found at: http://www.wwarn.org/ partnerships/study-groups/act-africa-baseline-study-group.

TWorldWide Antimalarial Resistance Network (WWARN), Oxford, UK Full list of author information is available at the end of the article

(c) 2014 Dahal and WWARN ACT Africa Baseline Study Group; licensee BioMed Central Ltd. This is an Open Access article distributed under the terms of the Creative Commons Attribution License (http://creativecommons.org/licenses/by/4.0), which permits 


\section{Authors' details}

${ }^{1}$ WorldWide Antimalarial Resistance Network (WWARN), Oxford, UK. ${ }^{2}$ Centre for Tropical Medicine, Nuffield Department of Clinical Medicine, University of Oxford, Oxford, UK.

Published: 22 September 2014

doi:10.1186/1475-2875-13-S1-P24

Cite this article as: Dahal and : Clinical determinants of early

parasitological response after ACT treatment in patients diagnosed with uncomplicated malaria in Africa: a pooled analysis of individual patient data. Malaria Journal 2014 13(Suppl 1):P24.

Submit your next manuscript to BioMed Central and take full advantage of:

- Convenient online submission

- Thorough peer review

- No space constraints or color figure charges

- Immediate publication on acceptance

- Inclusion in PubMed, CAS, Scopus and Google Scholar

- Research which is freely available for redistribution

Submit your manuscript at www.biomedcentral.com/submit 